\title{
(อ) OPEN ACCESS \\ Hepatitis D virus in 2021: virology, immunology and new treatment approaches for a difficult-to-treat disease
}

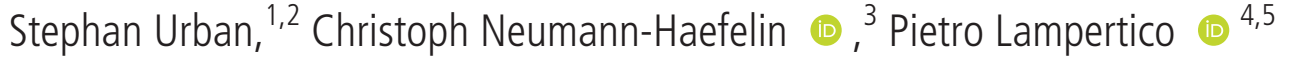

'Department of Infectious Diseases, Molecular Virology, University Hospital Heidelberg, Heidelberg, Germany

'German Center for Infection Research (DZIF) - Heidelberg Partner Site, Heidelberg,

Germany

${ }^{3}$ Department of Medicine II, Freiburg University Medical Center, Faculty of Medicine, University of Freiburg, Freiburg, Germany

${ }^{4}$ Division of Gastroenterology and Hepatology, Fondazione IRCCS Ca' Granda Ospedale Maggiore Policlinico, Milan, Italy ${ }^{5}$ CRC "A. M. and A.

Migliavacca" Center for Liver Disease, Department of Pathophysiology and Transplantation, University of Milan, Milan, Italy

\section{Correspondence to}

Dr Christoph Neumann-Haefelin Department of Medicine II, University of Freiburg, 79106 Freiburg, Germany; christoph.neumann-haefelin@ uniklinik-freiburg.de

SU and $\mathrm{CN}-\mathrm{H}$ contributed equally.

Received 12 April 2021 Accepted 26 May 2021 Published Online First 8 June 2021

Check for updates

(c) Author(s) (or their employer(s)) 2021. Re-use permitted under CC BY-NC. No commercial re-use. See rights and permissions. Published by BMJ.

To cite: Urban S, NeumannHaefelin C, Lampertico P. Gut 2021:70:1782-1794.

\section{ABSTRACT}

Approximately $5 \%$ of individuals infected with hepatitis $B$ virus (HBV) are coinfected with hepatitis D virus (HDV). Chronic HBV/HDV coinfection is associated with an unfavourable outcome, with many patients developing liver cirrhosis, liver failure and eventually hepatocellular carcinoma within 5-10 years. The identification of the $\mathrm{HBV} / \mathrm{HDV}$ receptor and the development of novel in vitro and animal infection models allowed a more detailed study of the HDV life cycle in recent years, facilitating the development of specific antiviral drugs. The characterisation of HDV-specific CD4+ and CD8+T cell epitopes in untreated and treated patients also permitted a more precise understanding of HDV immunobiology and possibly paves the way for immunotherapeutic strategies to support upcoming specific therapies targeting viral or host factors. Pegylated interferon- $\alpha$ has been used for treating HDV patients for the last 30 years with only limited sustained responses. Here we describe novel treatment options with regard to their mode of action and their clinical effectiveness. Of those, the entry-inhibitor bulevirtide (formerly known as myrcludex B) received conditional marketing authorisation in the European Union (EU) in 2020 (Hepcludex). One additional drug, the prenylation inhibitor lonafarnib, is currently under investigation in phase III clinical trials. Other treatment strategies aim at targeting hepatitis $B$ surface antigen, including the nucleic acid polymer REP2139Ca. These recent advances in HDV virology, immunology and treatment are important steps to make HDV a less difficult-to-treat virus and will be discussed.

\section{INTRODUCTION}

The human hepatitis D virus (HDV) is unique among animal viruses. Enveloped in the hepatitis B virus (HBV) surface proteins, HDV constitutes the smallest human virus with a diameter of $35-36 \mathrm{~nm}$ (figure 1A). HDV requires $\mathrm{HBV}$ as a helper for entry into hepatocyte, intrahepatic spread and dissemination between its hosts. ${ }^{12}$ Although recent in vitro findings indicate that HDV may propagate independent from HBV, using envelope glycoproteins from several virus genera such as vesiculovirus, flavivirus and hepacivirus including hepatitis $\mathrm{C}$ virus (HCV), ${ }^{3}$ clinical investigations confirm its strong association with HBV infection (hepatitis B surface antigen, HBsAg positivity). ${ }^{4-6}$ Some estimates suggest that up to 60 million individuals may be infected with $\mathrm{HDV}^{78}$ however, another meta-analysis indicates that 12 million people are affected. ${ }^{9}$ HBV/HDV coinfection is associated with a more severe course
Key messages

- At least 12 million individuals infected with hepatitis B virus (HBV) are coinfected with hepatitis $D$ virus (HDV) and have a high risk to develop liver cirrhosis and hepatocellular carcinoma within a few years.

- Until 2020, there was no specific treatment option for the large majority of these patients; off-label use of pegylated interferon- $\alpha$ (pegIFN $\alpha$ ) displays only approx. twenty per cent off-therapy virological response rates and is contraindicated in many patients.

- The identification of sodium taurocholate cotransporting polypeptide (NTCP) as cell entry receptor for both, HBV and HDV, allows the development of novel cell culture models and contributes to the development of novel treatment strategies.

- Beside de novo entry of virions via NTCP, cell division is an important mechanism of HDV spread; thus, combination therapies targeting these different mechanisms of viral spread are expected to show synergistic effects.

- Characterisation of HDV-specific immune responses will contribute to a better understanding of the mechanisms of HDV clearance versus persistence. It may also lead the way to novel treatment concepts, combining compounds that target host and/ or viral targets and immunotherapeutic interventions.

- Three novel anti-HDV compounds target host factors: the entry inhibitor bulevirtide (BLV, Hepcludex), the prenylation inhibitor lonafarnib (LNF), and the nucleic acid polymer REP2139Ca.

- BLV was approved for conditional marketing in Europe in 2020. BLV in combination with (offlabel) pegIFN $\alpha$ for 48 weeks or as monotherapy for a longer duration may allow sustained virological responses in a substantial proportion of patients.

- LNF and REP2139Ca also display encouraging response rates but additional data from phase III trials (ongoing for LNF) will be required prior to final assessment and possible approval by regulatory authorities.

of the diseases and an increased mortality compared with HBV monoinfection. Simultaneous infection with HBV and HDV of adults results in clearance 
A

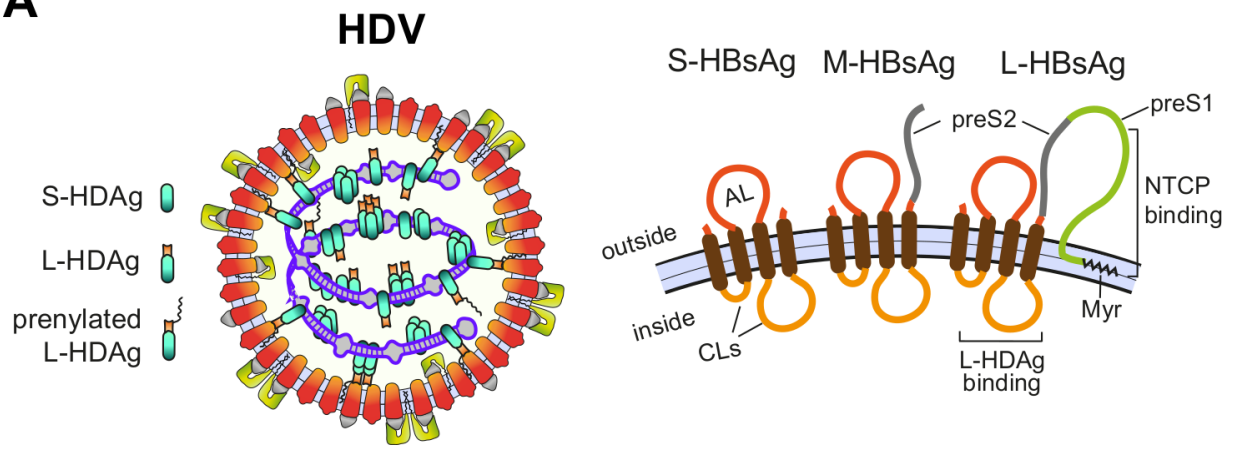

B

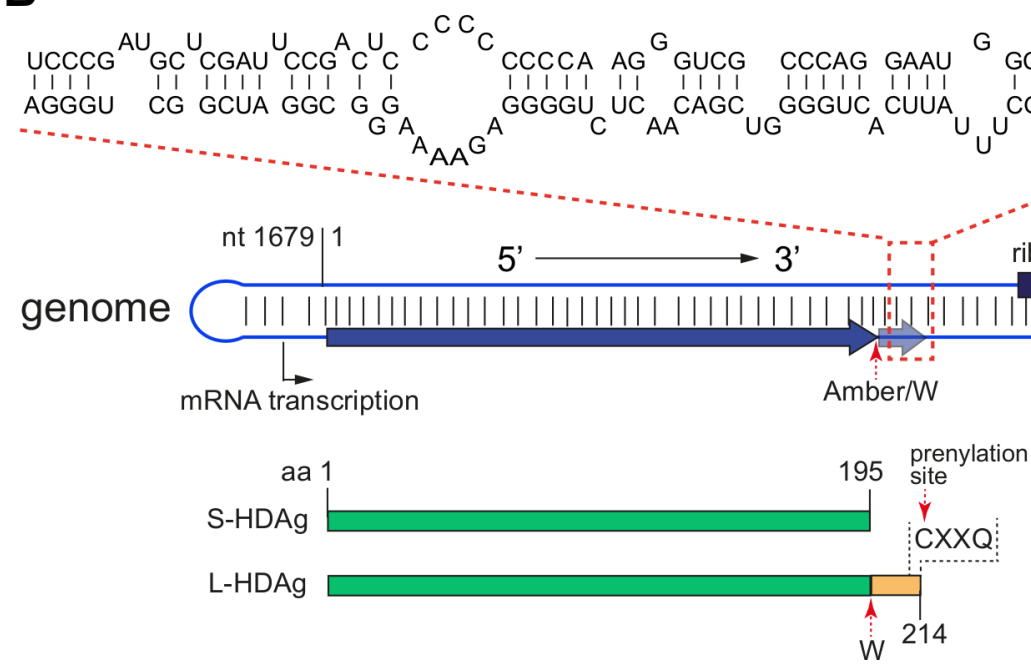

Figure 1 Structures of HDV virion and genome. (A) Schematic representation of HDV virion (left) and envelope proteins (right). HDV virion has a ribonucleoprotein (RNP) complex inside and an HBV derived envelope outside. The RNP consists of the HDV genome and two isoforms of hepatitis D antigen (HDAg), L-HDAg and S-HDAg. Prenylation of L-HDAg is essential for envelope acquisition. The envelope contains three HBV envelope proteins: small-HBsAg (S-HBsAg), medium-HBsAg (M-HBsAg) and large-HBsAg (L-HBsAg). M and L share the same sequence with $\mathrm{S}$, however, contain $\mathrm{N}$-terminal extensions: preS2 for $\mathrm{M}$ and preS1 plus preS2 for $\mathrm{L}$. The preS1 domain of $\mathrm{L}$ is critical for binding of the receptor sodium taurocholate cotransporting polypeptide (NTCP), while the cytosolic loops (CLs) are important for encapsulation of HDV RNP through interaction with HDAg. (B) HDV genome structure and key elements. As a single-strand circular RNA, HDV genome forms an unbranched rod-like structure through high rate of intramolecular base-pairing. A representative region consisting of short stems and bulges is depicted on top. S-HDAg and L-HDAg are encoded by unedited and adenosine deaminases acting on RNA 1 (ADAR1)-edited (Amber stop codon to TGG (W)) genomic RNAs, respectively. The C terminal prenylation motif (CXXQ) is indicated. The numbering of nucleotide and protein sequences is based on a HDV genotype one strain (GenBank: M21012.1). HBsAg, hepatitis B surface antigen; HBV, hepatitis B virus; HDV, hepatitis D virus; L-HDAg, large HDAg; S-HDAg, Small HDAg.

of both viruses in the majority of individuals. In contrast, superinfection of an HBV-infected patient with HDV typically results in the development of persistent HBV/HDV coinfection which may lead to liver cirrhosis, liver failure and eventually hepatocellular carcinoma (HCC) within short time. Indeed, 50\%-70\% of patients with chronic HBV/HDV coinfection develop cirrhosis within 5-10 years after diagnosis, corresponding to a threefold increase compared with HBV-monoinfected patients. ${ }^{10}$ The risk for HCC development is increased compared with HBV monoinfection with an odds ratio (OR) of 1.28-2.77, depending on the selection of studies included in the meta-analysis. ${ }^{11}$ Due to this increased complication rate, HDV coinfected patients account for approx. 25\% of HBsAg-positive liver transplant recipients in the European Liver Transplant Registry. ${ }^{10}$ Until recently, no approved antiviral treatment was available against HDV, thus, a more precise understanding of HDV virology and anti-HDV immune responses is essential to develop and establish novel therapeutic regimens.

\section{HDV STRUCTURE, REPLICATION, MECHANISMS OF PERSISTENCE AND ANTIVIRAL TARGETS} Molecular biology and the burden of HDV infection HDV genotypes and endemic hotspots

Due to the sequence variations found in HDV isolates, eight clades, termed genotypes $1-8$, have been classified. ${ }^{12}$ They show remarkable differences in their replication efficacies. ${ }^{13}$ Genotype 1 is globally scattered while HDV genotypes $2-8$ can be attributed to distinct geographic regions in the world. While the HDV median prevalence in HBsAg carriers is estimated to about $5 \%$, it typically manifests in hotspots ${ }^{10}$ like Mongolia, the Middle East, Usbekistan or parts of South America where up to $80 \%$ of HBsAg carriers also display markers (anti-HDV antibodies, HDV RNA) of an HDV infection. ${ }^{10}$ Due to the large gaps of knowledge on reliable epidemiological data HDV prevalence may be profoundly underestimated and needs more attention in the future. ${ }^{7}$ 


\section{HDV genome structure}

The HDV genome consist of 1672-1697 ribonucleotides (genotype-dependent) and forms a single stranded covalently closed circular RNA molecule of negative polarity (defined in relation to the $(+)$ stranded mRNA encoding the hepatitis $\mathrm{D}$ antigen (HDAg)). Both, genomic and antigenomic RNA is characterised by a high degree of self-complementarity $(>70 \%)$ leading to recurrent back-folded stretches of base paired rods, that are interrupted by short loops. ${ }^{14}$ This peculiar structure resembles the structure of plant viroid RNA and mimics a DNA double helix (figure 1B). Different from plant viroids, HDV RNA associates with the viral HDAg but also the protein bromodomain adjacent to zinc finger domain 2B (BAZ2B), involved in chromatin remodelling. ${ }^{15}$ Such 'molecular mimicry' complexes of dsDNA enables the host DNA-dependent RNA-polymerase (Pol II) to accomplish RNA-dependent RNA synthesis. HDAg is encoded as two isoforms within a segment of the HDV genome, namely the small HDAg (S-HDAg, 195 aa, $24 \mathrm{kDa}$ ) and the large HDAg (L-HDAg, $214 \mathrm{aa}, 27 \mathrm{kDa}$ ). While S-HDAg is necessary to initiate and maintain replication, L-HDAg negatively regulates replication and triggers envelopment of the virus into the HBV surface proteins. Both antigens are post-translationally modified in order to fulfil their distinct functions. ${ }^{12}$

\section{HDV replication and envelopment of HDV ribonucleoproteins into $\mathrm{HBsAg}$}

Following entry and delivery of the genomic HDV ribonucleoprotein complex (RNP) to the nucleus of an infected hepatocyte, S-HDAg-encoding mRNA is transcribed and translated. S-HDAg expression is required for maintenance of nuclear RNA replication functioning as a 'reprogramming factor' to adopt Pol-II to an RNA substrate. During RNA synthesis, which proceeds via consecutive rolling circle mechanisms that switch between $(-)$ and $(+)$ strand synthesis (see reference 2 and figure 2A), the de novo synthesised genomic HDV RNA underlies editing by the cellular ADAR- 1 enzyme. ${ }^{16}$ This editing results in a mutation in the UAG stop codon of the S-HDAg open reading frame to a UGG (Trp-codon). After transcription of the corresponding HDAg-mRNA, the ribosome introduces a Trp residue and further on a C-terminal extension of 19-20 aa (genotype dependent) leading to L-HDAg. Accordingly, both HDAgs share the N-terminal S-HDAg domain and are able to bind genomic and antigenomic HDV RNA to form RNPs (figure 1). In addition, L-HDAg is subjected to prenylation by the cellular farnesyltransferase (target of lonafarnib (LNF)) at a conserved Cys-residue (Cys-211) within the C-terminal extension. When HBsAg is expressed in the same cell, prenylated L-HDAg recognises a hydrophobic element within the cytosolic loop of the small HBV envelope protein (S-HBsAg). Since S-HBsAg alone triggers self-assembly and secretion of HBV subviral particles (SVPs), expression of HBsAg in RNP containing cells is sufficient for HDV secretion. Through incorporation of the large HBV envelope protein L-HBsAg, the particles gain infectivity and support transmission into sodium taurocholate cotransporting polypeptide (NTCP)-receptor expressing cells to disseminate within the liver (figure 2A) and between hosts ${ }^{17}$ (for more details see reference ${ }^{12}$ ). The HBV $\mathrm{M}$-protein is redundant for both, particle release and entry. ${ }^{18} 19$ Since in a natural infection HBsAg can be expressed from both HBV cccDNA (in HBV replicating cells) and chromosomally integrated HBV DNA, ${ }^{20} 21$ enveloped HDV serum RNA particles may arise from both sources.
Receptor interaction and the consequence of HBV integration Liver tropism and hepatic receptors of HBV and HDV

The liver tropism of HBV and HDV is primarily determined by a specific interaction of an extended receptor binding domain (RBD) (aa 1-75) in the preS-1-part of the HBV L-protein ${ }^{18}$ and the hepatic NTCP receptor. ${ }^{22}{ }^{23}$ NTCP interaction of HBV and HDV requires prior attachment to heparan sulphate proteoglycans (HSPGs) ${ }^{1}$ (figure 2A). This mandatory step presumably triggers the release of the otherwise hidden preS-receptor binding site. HSPG-requirement explains how neutralising anti-HBsAgspecific antibodies, although they do not directly interfere with preS/NTCP-interaction, block entry and control infection.

NTCP exclusively locates at the basolateral/sinusoidal membrane of differentiated, polarised hepatocytes. NTCPexpression ceases when differentiated hepatocytes proliferate. ${ }^{24}$ NTCP is also downregulated in transformed cell lines of hepatic origin such as HepG2, HuH7 and Hep3B. Thus, proliferating normal hepatocytes, transformed hepatoma cells, and probably also tumour cells in HCC lack NTCP ${ }^{25}$ and do not support entry of HBV and HDV. Though, proliferating cells support spread of HDV RNA (depending on their interferon (IFN) activated state) ${ }^{2627}$ but loose HBV cccDNA (figure 2B). ${ }^{28}$ A deeper understanding of these peculiar differences of HDV and its helper HBV will be crucial for understanding persistence and is important for the development of successful therapeutic interventions.

\section{Studying HDV replication in vitro}

Constitutive NTCP expression provides susceptibility to HDV infection of hepatic and even non-hepatic cells. Different NTCPexpressing cell lines have been developed in recent years and are used as HDV/HBV infection systems to study fundamental aspects of virus replication but also for the identification of novel drug candidates. Although NTCP-expression is sufficient to permit HDV entry and the onset of replication, assembly and secretion of viral particles cannot be achieved due to the lack of the HBV envelope proteins required for virus release. This can be overcome by cell lines that express both, the NTCP receptor and the HBV envelope proteins. ${ }^{29}{ }^{30}$ Such cell lines support the complete replication cycle of HDV with entry, initiation of RNA replication, processing of L-HDAg and release of infectious progeny virus. Remarkably, coexpression of NTCP and its ligand (the L-protein) neither interferes with HDV particle secretion nor does it induce receptor downmodulation as described for many viruses (eg, $\mathrm{HIV}^{31}$ or even the duck $\mathrm{HBV}^{32}$ ). This has important clinical implications on intrahepatic persistence of HDV RNA and the envisaged results of treatment responses. Different in vivo models for HDV have been developed and are summarised in. ${ }^{33}$

\section{Consequences of HBV integration and clonal expansion of integrants}

One implication of HBV integration is that the replication space of HDV in an HBV-infected liver may not be restricted to cells that transcribe HBsAg from HBV cccDNA but also to hepatocytes that express HBsAg from integrated HBV DNA. Such integrates establish instantly when double stranded linear HBV DNA-containing particles, a 'by-product' of HBV replication, enter hepatocytes via NTCP. ${ }^{34}$ Early during acute HBV infection, the integration rate is low and restricted to single cells, however under circumstances like continuous inflammation accompanied by liver regeneration, or transformation, such cells clonally expand. Although integrated HBV DNA cannot function as a 'provirus' (like retroviruses), it characteristically encodes HBV 

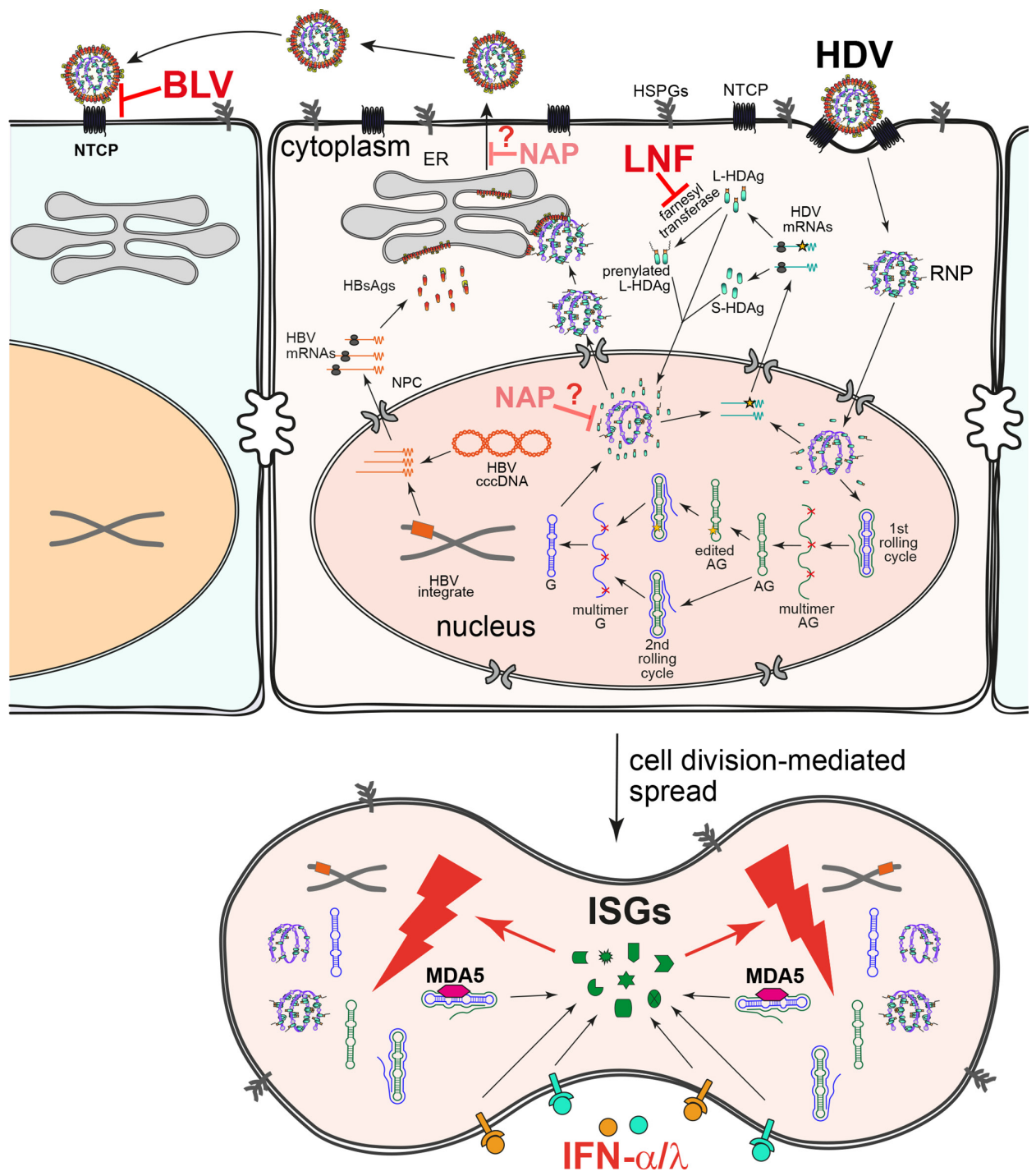

Figure 2 HDV life cycle, spreading pathways and drug targets. HDV virions first attach to heparan sulfate proteoglycans (HSPGs) and then to the viral receptor NTCP to enter host cells. After membrane fusion, the ribonucleoprotein (RNP) is released and further transported to the nucleus to initiate RNA replication. The incoming genome (G) serves as the template for the first rolling circle amplification. The resulting antigenome (AG) multimers are cleaved in cis by the intrinsic ribozyme and ligated into circular monomers. After a second rolling cycle using the AG as the template, HDV G multimers are synthesised and further cleaved to produce monomers. The HDV AG might be edited by ADAR1, yielding an extended HDAg ORF that produces L-HDAg, some of that is further prenylated. S-HDAg and L-HDAg (intact and prenylated) are transported into the nucleus to regulate virus replication or bind to the HDV RNA to form RNP. The G-containing RNP can be exported to the cytoplasm and encapsulated into HBV envelope through the interaction between L-HDAg and S-HBsAg. HDV virions are released through the ER-Golgi secretory pathway. besides the HBV envelopedependent de novo infection, HDV can also spread through division of infected cells in an HBV-independent manner (below). Bulevirtide (BLV) blocks de novo infection by efficient binding of the viral receptor NTCP. Lonafarnib (LNF) prevents the prenylation of L-HDAg by inhibiting the farnesyl transferase and consequently impairs HDV assembly and secretion. The target(s) of nucleic acid polymer (NAP) is unclear. It may inhibit assembly/ release of HDV virions and/or HDV ribonucleoprotein assembly via direct interaction with the HDAg. IFNs, including MDA5-mediated HDV-induced IFNs and therapeutic IFN $\alpha$ and IFN $\lambda$, induce IFN stimulated genes (ISGs) which profoundly suppress HDV amplification during cell division. HBV, hepatitis B virus; HDV, hepatitis D virus; IFN, interferon; L-HDAg, large hepatitis D antigen; NTCP, sodium taurocholate cotransporting polypeptide; S-HBsAg, small hepatitis B surface antigen.

envelope proteins which, when located in transcriptionally active sites of the chromosome and contribute to serum HBsAg in patients. If such clonally expanded 'hepatocyte islands' carrying identical integrations maintain NTCP expression, they constitute HBV cccDNA-independent replication space for HDV in the liver. Considering that cccDNA gets lost during cell division, ${ }^{28} 35$ it is reasonable to assume that especially in HBeAgnegative chronic carriers of $\mathrm{HBV}$, who have been shown to produce the majority of HBsAg from integrates, ${ }^{36} \mathrm{HDV}$ serum
RNA may significantly originate from cells with $\mathrm{HBV}$ integrates. Thus, therapeutic approaches targeting cccDNA would only partially affect HDV.

Cell division mediated intrahepatic spread of HDV RNA

Besides spreading of enveloped HDV via an NTCP-receptor dependent de novo infection pathway, another mode of HDV RNA dissemination has been described recently. ${ }^{26}$ It is 
characterised by the direct transfer of replication competent HDV RNA between cells during mitosis. This process can proceed in the absence of HBsAg. To what extent it contributes to HDV persistence in the liver of infected patients is unknown and needs to be investigated in the future. The effectiveness of cell division-mediated RNA spread however profoundly depends on recognition of replicating HDV RNA by $M D A 5^{37}$ and the degree of IFN induction (figure $2 \mathrm{~B}$ ).

\section{Interfering with viral replication Viral targets}

In contrast to other RNA viruses that encode RNA-dependent RNA-polymerases (RdRP) for replication and mRNA synthesis, HDV recruits and reprogrammes the cellular Pol II to achieve these goals. ${ }^{2}$ Accordingly, an important viral drug target (the RdRP) is lacking. Nevertheless, crucial steps in the viral life cycle like the ribozyme-mediated self-cleavage of genomic and antigenomic RNA oligomers or the HDAg-dependent regulation of RNA replication and mRNA synthesis are attractive viral structures suitable for drug targeting. Inactivation of the S-HDAg could induce a selective shut down of RNA synthesis (eg, through abrogation of its RNA binding activity or inactivation of its cofactor function for Pol II). Alternatively, abolition of the interaction of the prenylated C-terminus of L-HDAg with the cytosolic loop in the HBV S-domain by small molecules would inhibit virus release similar to LNF, which targets the corresponding host enzyme (see below and figure 2A). No such drugs have been identified so far, however applying the new replication systems mentioned above will facilitate screening approaches and drug candidate identification in the future.

\section{Cellular targets}

At present all strategies that have been clinically developed address cellular targets. Host factor targeting bears the problem that the drug inactivates the cellular function of the target and thus, besides affecting the virus, also induces side effects. Conversely, host factor targeting profits by a higher barrier to develop drug resistance. The most advanced drug against HDV is bulevirtide (BLV), formerly called Myrcludex B. BLV addresses NTCP thereby blocking virus entry. ${ }^{17}$ Another drug, LNF, inactivates farnesyltransferase, thereby preventing envelopment of RNPs with HBsAg (figure 2A). ${ }^{38}$ While interference with prenylation results in a direct inhibition of virion release on target engagement, entry inhibition affects serum HDV-RNA levels through an indirect effect, namely the reduction of the pool of HDV producing cells by cell turnover through sustained inhibition of de novo infection. According to these differences in their mode of action, the kinetics and the degree of drugmediated suppression of HDV serum RNA levels differ substantially. The third drug that is presently developed clinically are nucleic acid polymers (NAPs). These molecules have been associated with multiple modes of action including HBsAg secretion inhibition of SVPs and virions by targeting (a) host factor(s) and direct interaction with HDAg. ${ }^{39} 40$ In addition, it has been assumed that NAPs impact immunological mechanisms by yet ill understood mechanisms. ${ }^{41}$ Lastly, IFN- $\alpha$ (IFN $\alpha$ ), an off-label drug used for chronic HBV/HDV coinfection since the 1980s, inhibits HDV replication, likely through induction of antiviral interferon stimulated genes (ISGs) and/or adaptive immunity (figure 2B). Notably, IFNs (IFN $\alpha$ and IFN $\lambda$ ) can profoundly suppress cell division-mediated HDV spread, which is not achievable by entry or release inhibition. ${ }^{27}$
Beside these well-characterised host factors additional approaches using siRNA or drug libraries ${ }^{42}$ in susceptible cell lines will allow to identify novel host factors in the future and it will be a challenging task to identify those that allow intervention and are tolerable regarding side effects.

\section{IMMUNE RESPONSE TO HDV Innate immunity Interferon}

IFNs are the main mediators of early containment of viral replication: They bridge the gap until adaptive immunity is induced and play a crucial role in this induction process. While HBV as a 'stealth' virus undermines the IFN system by avoiding recognition in acute as well as chronic infection, ${ }^{43-45}$ HDV resembles $\mathrm{HCV}^{46}$ and induces an IFN response, but may have several methods to counteract or even take advantage of it. Indeed, induction of an IFN response has been demonstrated in cell culture models as well as in a mouse model of acute and chronic coinfection. ${ }^{3747-49}$ Induction is limited to IFN $\beta$ and $\lambda$, but not $\alpha$, and compared with other RNA viruses (eg, Sendai virus) rather weak. ${ }^{37}$ Recognition of RNA intermediates is sensed by the pattern recognition receptor melanoma differentiation antigen 5 (MDA5) (figure 2B), but not retinoic acid inducible gene I (RIG-I) or toll-like receptor 3 (TLR3). ${ }^{37}$ Since MDA5 is preferentially localised in the cytoplasm, the exact mechanisms of HDV sensing is not yet clear. The suppressive effect of IFN $\alpha$ on HDV replication in vitro is more profound during an early stage of infection (eg, the establishment of replicative intermediates) in vitro, while established infections in the absence of cell division are less affected. ${ }^{37}{ }^{50}$ Importantly, IFN has a dominant effect on cell-division mediated HDV spread. ${ }^{27}$ This sensitivity of HDV to IFN during cell division is not yet understood on the molecular level but may be due to the resolution of the nuclei, exposure of viral RNA to induced ISGs, and the subsequent elimination/ degradation of HDV RNA. Of note, this finding has implications for future combination therapies with innate immune modulators (eg, TLR agonists) but also IFN (eg, IFN $\lambda$ ).

HDV-induced IFNs may suppress HBV replication, partially explaining that patients coinfected with HDV usually display low HBV viral loads. ${ }^{47}$ In addition, HDV may take advantage of the IFN response: it leads to IFN $\beta / \lambda$-mediated upregulation of HBV antigen presentation, resulting in increased T-cell induced HBV suppression and thus a further shift towards a dominance of HDV over HBV replication. ${ }^{51}$ How HDV counteracts the IFN response is so far only partially understood. There are conflicting results regarding the down-regulation of ISG transcription by HDV-mediated inhibition of phosphorylation and nuclear translocation of STAT1/2. ${ }^{374852}$ Alternatively, HDV may hide from recognition as well as clearance by the IFN system by compartmentalisation to the nucleus as well as protecting its RNA within the RNP as well as HBsAg. ${ }^{49}$

\section{Natural killer cells}

Natural killer (NK) cells are increased in frequency in the peripheral blood in chronic viral hepatitis, irrespective of the exact viral pathogen, however, they display a less activated phenotype and are compromised in cytolytic function and cytokine production. Untreated HBV/HDV coinfected patients tend to have even higher peripheral NK cell frequencies compared with patients with other hepatitis virus infections, however, this difference is most likely due to the impact of disease activity and severity on NK cell frequency and function rather than the viral pathogen itself. $^{53}$ These data also suggest, but do not proof, a role of NK 
cells in pathogenesis and disease progression. Of note, cytomegalovirus (CMV)-associated adaptive-like NK cell subsets are not affected by HDV or other hepatitis viruses. ${ }^{54}$ Early studies indicated a boost of NK cell activity during therapy in HBV/ HDV coinfected patients that responded to IFN $\alpha$ treatment (clearance of intrahepatic delta antigen). ${ }^{55}$ More recent analysis demonstrated a change in NK cell differentiation during IFN $\alpha$ treatment, with selective loss of terminally differentiated NK cells, enrichment in immature NK cell subsets, and functional impairment. ${ }^{56} \mathrm{~A}$ high percentage of CD $56^{\mathrm{dim}} \mathrm{NK}$ cells at baseline was positively associated with treatment response, ${ }^{56}$ suggesting an important role of NK cells in IFN-induced viral control.

\section{Mucosa-associated invariant T cells}

Mucosa-associated invariant $\mathrm{T}$ (MAIT) cells occur in high frequencies in the liver. ${ }^{57}$ In patients with $\mathrm{HBV} / \mathrm{HDV}$ coinfection, MAIT cells are activated, most likely due to increased interleukin 12 (IL-12) and IL-18 secretion by activated monocytes, leading to functional impairment and subsequent progressive loss of peripheral as well as intrahepatic MAIT cells with progressive disease. $^{58}$

\section{Adaptive immune response}

Antibody response

Anti-HDV antibodies are detectable in rather low titres in acute-resolving HDV infection, but at higher titres in persistent infection. $^{59}$ In patients with active hepatitis, anti-HDV IgM often persist at high titres. Thus, anti-HDV antibodies contribute little to viral control and clearance, most likely due to the lack of neutralising activity.

\section{T cell response}

Virus-specific $\mathrm{T}$ cells are the drivers of elimination in acuteresolving HBV as well as HCV infection. The important contribution of cellular adaptive immunity in HBV and HCV clearance have been demonstrated by (1) longitudinal studies demonstrating temporal association between the onset of virus-specific T-cell responses and viral elimination, (2) HLA association studies revealing protective class I and II alleles, and (3) direct antibody-mediated depletion of CD4+ and CD8 $+\mathrm{T}$ cells in the chimpanzee model. ${ }^{60}$ For HBV/HDV coinfection, the role of $\mathrm{T}$ cells has not been well defined, since adequate animal models are lacking and few HDV-specific T cell epitopes with defined HLA restriction were fine-mapped so far.

Indeed, the HDV-specific CD4+ Tcell epitope repertoire has been analysed in two studies at a single-epitope resolution. ${ }^{6162}$ Approx. 30\%-40\% of untreated HDV-infected patients displayed HDV-specific CD4+ T cell responses usually targeting 1-3 distinct epitopes. These responses were weak and only detectable after antigen-specific culture. CD4+ T cells targeted epitopes throughout the L-HDAg, with some preference for the $\mathrm{N}$-terminal region (figure 3 ). In addition, CD4+ T cell epitopes
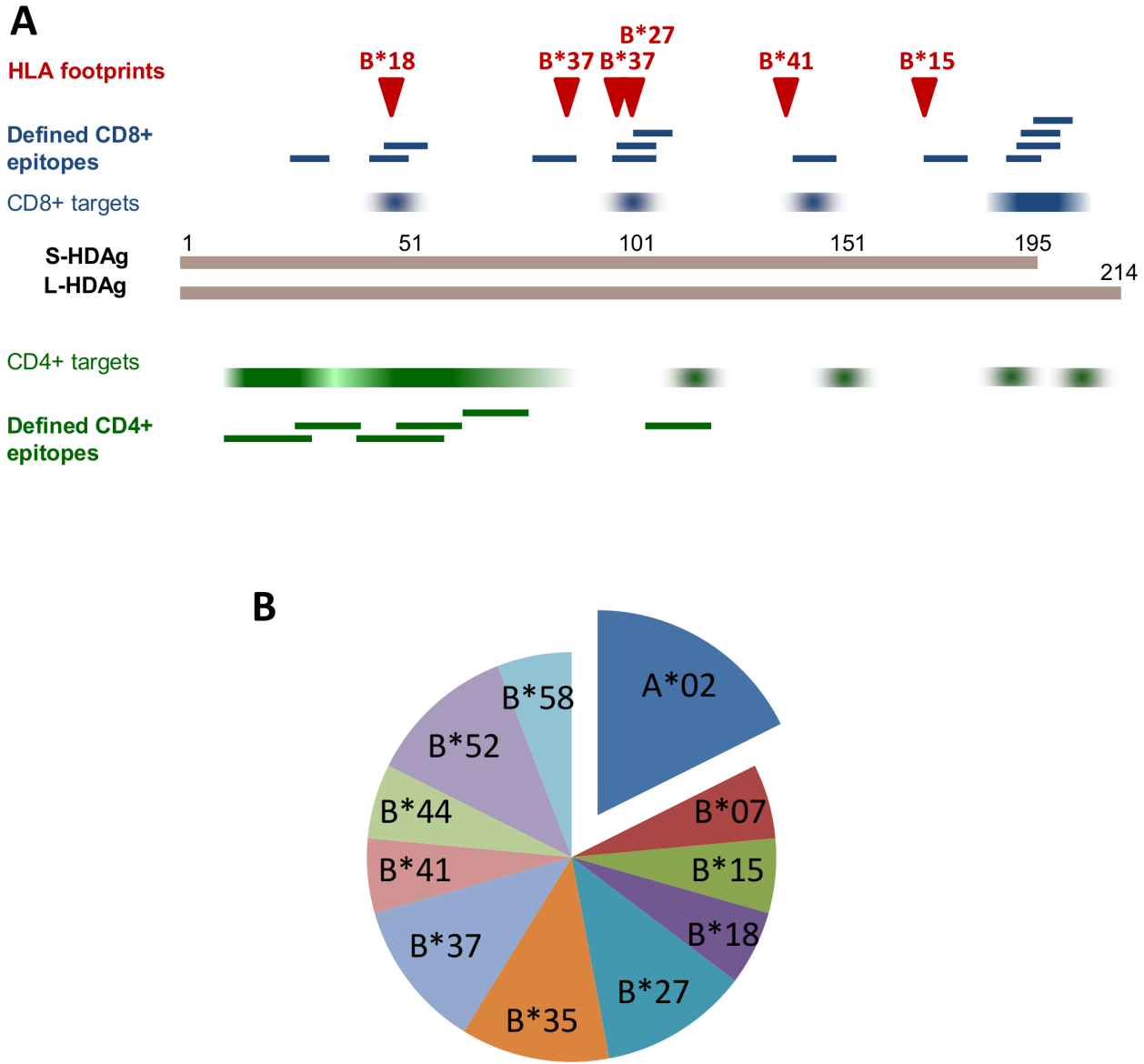

Figure 3 HDV regions targeted by HDV-specific CD4+ and CD8+ T cell epitopes. (A) Dominantly targeted CD8+ and CD4+ epitope regions (identified in olp studies) are indicated in blue and green colour, respectively, with intensity representing frequency of recognition. Fine-mapped CD8+ and CD4+ T cell epitopes are indicated by blue and green bars, respectively. HLA class I associated HDV polymorphisms ('HLA footprints') that correlate to fine-mapped epitopes are depicted by red arrowheads. (B) HLA restriction of fine-mapped HDV-specific CD8+ T cell epitopes, demonstrating a clear dominance of HLA-B restriction. HDV, hepatitis D virus; L-HDAg, large hepatitis D antigen; S-HDAg, small HDAg. 
displayed promiscuous HLA restriction. The two studies led to conflicting results regarding the association between detectable HDV-specific CD4 + T cell responses and clinical parameters. Nisini et al were able to detect HDV-specific CD4+ T cell responses only in patients with normal alanine aminotransferase (ALT; HDV-RNA data are not available for this early study). ${ }^{62}$ Landahl et al, in contrast, did not observe an association between HDV-specific CD4 + T cell responses and HDV-RNA status (18 untreated patients with detectable RNA vs 13 untreated patients with undetectable RNA), HDV viral load, transaminases or HBsAg levels. They found, however, an association between HDV-specific CD4 + T cell responses and low HBV viral load, ${ }^{61}$ paralleling the association between $\mathrm{HBV}$-specific T-cell responses and low HBV viral load found in inactive HBsAg carriers and nucleoside/nucleotide analogue-treated patients in chronic HBV monoinfection. ${ }^{63}$

HDV-specific CD8 + T cell responses were comprehensively analysed only recently. ${ }^{61} 6465$ Indeed, after peptide-specific culture using overlapping L-HDAg peptides, approx. 40\% and $70 \%$ of untreated and LNF-treated patients, respectively, with chronic HBV/HDV coinfection displayed HDV-specific CD8+ T cell responses. ${ }^{6165}$ HDV-specific CD8 + T cell epitopes clustered in the C-terminal part of HDAg that is unique to its large isoform (L-HDAg) and were dominantly restricted by HLA-B alleles ${ }^{6165}$ (figure 3). Like HDV-specific CD4 + T cells, HDV-specific CD8 + T cells display low ex vivo frequencies similar to HBV- and HCV-specific CD8+ T cell frequencies, but substantially lower compared with Eppstein Barr Virus (EBV) -specific, CMV-specific and influenza-specific CD8+ T cells. ${ }^{64}$ Earlier studies in a small number of patients found positive HDV-specific CD8 + T cell responses in patients with resolved HDV infection only. ${ }^{66}{ }^{67}$ In the more recent and comprehensive analyses, however, no difference was observed for the detection rate of proliferative HDV-specific CD8+ Tcell responses between patients with resolved HDV infection and patients with chronic HBV/HDV coinfection. ${ }^{616465}$ In comparison to previous findings in $\mathrm{HBV}$ and $\mathrm{HCV}$ infection, where patients with spontaneously resolved infection usually display substantially stronger T-cell responses on peptide stimulation, this finding is unexpected. It may be explained by the fact that many patients with resolved HDV infection are still chronically infected with HBV, leading to continued T-cell exhaustion, or long periods of HDV viraemia in many patients possibly leaving a functional scar (eg, partial exhaustion) on HDV-specific CD8 + T cells even after viral clearance similar to the findings in $\mathrm{HCV}$-infected patients after DAA-mediated cure. ${ }^{68}$ In line with these considerations, IFN $\gamma$ responsiveness of HDV-specific CD8 + T cells correlated negatively with HDV viral load in untreated patients in one study, ${ }^{65}$ but with HBV viral load in the other study. ${ }^{61}$

The mechanisms of HDV-specific CD8 + Tcell failure in chronic HBV/HDV coinfection have been addressed recently. ${ }^{64656769}$ There is evidence that the two main mechanisms known for other viral infections also apply to HDV: mutational viral escape and CD8 + T cell exhaustion (figure 4). A large international collaborative study analysed HLA class I-associated viral sequence polymorphisms in 104 untreated patients with chronic HBV/HDV coinfection. Several HDVspecific CD8 + T cell epitopes were identified and viral sequence variations in these epitopes were confirmed to mediate viral escape by functional analyses. ${ }^{6467}$ Of note, several of the newly identified HDV-specific CD8 + T cell epitopes corresponded to HDV-specific CD8 + Tcell epitopes identified by using overlapping peptides (figure 3), ${ }^{6165}$ indicating that the repertoire of HDV-specific CD8 + T cell epitopes is limited. Importantly, both approaches and all three studies consistently observed a dominance of HLA-B alleles in restricting HDV-specific CD8 + T cell responses. ${ }^{616465}$ Strikingly, the majority of CD8 + T cell epitopes as well as HLA-associated sequence polymorphisms was linked to quite rare HLA class I alleles, while most common HLA class I alleles such as HLA-A*02 seem to contribute little to the HDVspecific CD $8+$ T cell epitope repertoire. ${ }^{64}$ Thus, viral escape may have led to the extinction of HDV-specific CD8 + T cell epitopes restricted by common HLA class I alleles at the population level.
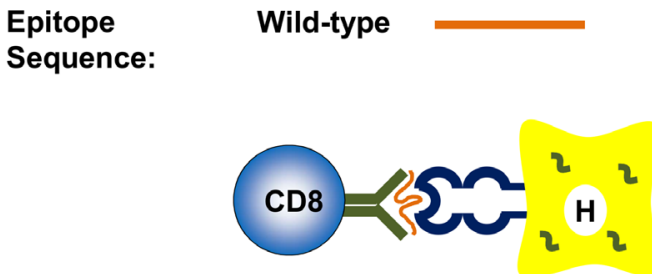

Antigen recognition:

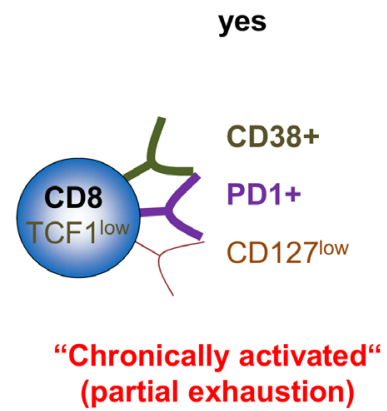

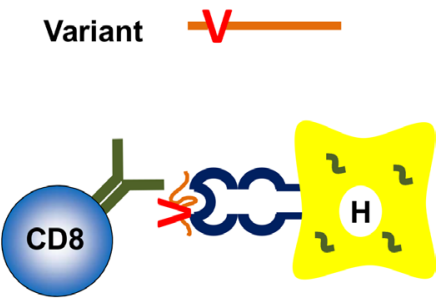

no (due to viral escape)

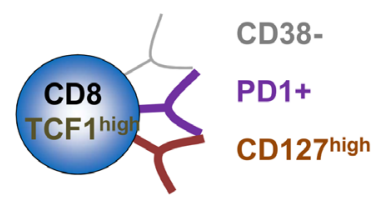

Memory-like

Figure 4 Mechanisms of HDV-specific CD8+ T cell failure. HDV-specific CD8+ T cells targeting viral epitopes with wild-type sequence display a chronically activated phenotype and are functionally partially exhausted (left), HDV-specific CD8+ T cells targeting viral epitopes with sequence variations (viral escape) do not recognise the antigen anymore and display a memory-like phenotype (right). HDV, hepatitis D virus. 
HDV-specific CD8 + Tcells targeting viral epitopes with mutated sequences displayed a memory-like phenotype $(\mathrm{CD} 127+$, programmed cell death protein $1[=(\mathrm{PD}-1)+, \mathrm{T}$ cell factor $1(\mathrm{TCF}-1)+)$ and low expression of activation markers such as $\mathrm{CD} 38,{ }^{64}{ }^{65}$ consistent with the phenotype of virusspecific CD8 + T cells lacking antigen stimulation due to viral escape in chronic HCV infection. ${ }^{70} \mathrm{HDV}$-specific CD8 + T cells that targeted viral epitopes without evidence of viral escape, however, displayed a different phenotype with higher expression of CD38 and lower expression of CD127 and TCF-1. ${ }^{65}$ These cells were, however, not terminally exhausted, since they displayed low levels of CD57 and-mostly strikingly—expressed multiple inhibitory/exhaustion markers to a lesser degree compared with HBV-specific, CMV-specific and EBV-specific $\mathrm{CD} 8+\mathrm{T}$ cells. ${ }^{65}$ While it is at first contraintuitive that virusspecific CD8 + T cells in the setting of the 'most severe' viral hepatitis display lower exhaustion markers compared with other persistent viral infections, this observation may partially explain the similar strength of HDV-specific CD8 + Tcell responses in resolved versus chronic infection. It is also in agreement with the previous report that HDV-specific $\mathrm{T}$ cells are functionally restored by the third signal cytokine IL-12 rather than by checkpoint inhibitors such as anti-PD-L1 or anti-CTLA4. ${ }^{69} \mathrm{CD} 38+$ HDV-specific CD8 + T cells, and thus HDV-specific CD8 + T cell targeting non-mutated HDV epitopes, were associated with increased aspartate aminotransferase (AST) levels, indicating, but by far not proving, a causative role of HDV-specific CD8+ T cells in immunopathology of chronic HBV/HDV coinfection. ${ }^{65}$

Some of the most important questions in HDV-specific immunity remain to be solved. For example, regarding the natural course of persistent infection, the precise mechanism of immunopathology leading to unfavourable outcomes in the majority of patients remains elusive. From an immunologist's perspective, the interplay between HBV-specific and HDV-specific immunity is a clear focus for further investigation, especially since current studies still 'ignore' the dual role of HBsAg as surface antigen of both, HBV as well as HDV. Lastly, and most important from a translational perspective: Are HDV-specific immune responses (at least partially) restored during therapy with novel antiviral strategies, similar as observed for HBV during NUC treatment and HCV during DAA therapy ${ }^{60}$ ? HDV-specific T-cell responses show little recovery during the treatment with pegylated IFN $\alpha$ (similar to what has been observed for HBV- and HCV-specific T-cell responses, likely due to the T-cell-suppressive effects of IFNo), but do they restore and play a role in viral clearance during BLV therapy? First analyses that were limited to three cases with cirrhosis could not readily identify such a T-cell restoration, ${ }^{71}$ however, further studies need to address this in larger patient cohorts also including less advanced disease. Of note, restoration of HDV-specific immunity by new antiviral treatments targeting host and/or viral targets may also pave the way for therapeutic vaccination that may be an attractive intervention in the setting of an otherwise 'suppressive' and not 'curative' treatment strategy.

\section{ANTI-HEPATITIS D TREATMENT Endpoints of therapy}

The ideal endpoint for any anti-HDV therapy would be HBsAg loss with anti-HBs seroconversion. Elimination of replicating HDV RNA from the liver in HBsAg positive patients would be an alternative, however, it would require biopsies from patients and is not applicable in clinical practice. A more practical primary endpoint outcome is serum or plasma HDV RNA (as a surrogate marker of liver HDV-RNA levels) below the limit of detection by a sensitive and specific PCR assay during therapy, at the end of treatment (EOT) and off-therapy, at least 24 weeks after treatment discontinuation. ${ }^{72}$ However, given the high risk of late post-treatment virological relapses described after IFN-based therapies, a sustained off-therapy response should be confirmed over time, well beyond 24 weeks after treatment discontinuation. The proportion of patients with $\mathrm{a} \geq 2 \log \mathrm{IU} / \mathrm{ml}$ decline of HDV RNA coupled with normal ALT have also recently been suggested as reasonable secondary endpoints for clinical trials. ${ }^{73}$ To comply with these stringent virological endpoints, it is of paramount importance to rely on commercially available, validated, WHO standardised, sensitive and specific HDV RNA assays that may allow to compare viral kinetics within as well as across studies. $^{73}$

\section{Current anti-HDV treatment \\ IFN $\alpha$}

Although not FDA or EMA approved, standard and pegIFN $\alpha$ treatments have been widely used as anti-HDV strategy in the last 20-30 years. PegIFNo is the only treatment regimen currently recommend by international guidelines. ${ }^{7-76} \mathrm{~A}$ 48-week course of weekly subcutaneous injections of pegIFNa suppresses HDV replication in approximately $20 \%-30 \%$ of the patients 24 weeks off therapy, yet with significant side effects. Continuous administration of IFN for more than 48 weeks may lead to a lower likelihood of disease progression, with $\mathrm{HBsAg}$ loss occurring in about $10 \%$ of these patients during long-term follow-up. ${ }^{77}$ Although the long term, off-treatment virological/ biochemical response induced by IFN treatment has been associated with improved outcomes, ${ }^{72} 73$ IFN has limited use in clinical practice given the fact that this drug is contraindicated in elderly people or in those with autoimmune disease stigmata or with advanced or decompensated liver disease. Moreover, many patients have been already unsuccessfully exposed to standard or pegIFN $\alpha$ in the past. Combination of pegIFN $\alpha-2 a$ with adefovir for 48 weeks $^{78}$ or with tenofovir disoproxil fumarate (TDF) for 96 weeks did not significantly improve the off-treatment virological responses. ${ }^{79}$ Of note, in approximately $50 \%$ of week 24 off-treatment responders, a late virological relapse was observed, further challenging the long-term effectiveness of this treatment. ${ }^{80}$

The general failure of IFN treatment to induce a long-term ( $>24$ weeks) sustained virological response on HDV may be due to the persistence of HDV in the liver even at very low $\mathrm{HBsAg}$ levels. This concept is supported by the observation that after liver transplantation, HDV can persist in the liver for many months even in the absence of liver HBV DNA/cccDNA and serum HBsAg and HDV RNA. ${ }^{81}$

\section{New anti-HDV strategies: completed phase II studies NAPs with pegIFN $\alpha$}

Phosphorothioate NAPs are oligonucleotides with a broad spectrum of inhibitory activity against several viruses, whose exact mechanism in HDV is still unknown (see previous section on virology).

In the non-randomised, open-label phase 2 REP301 study, 12 treatment-naïve non-cirrhotic patients with chronic HBV/HDV coinfection from Moldova received $500 \mathrm{mg}$ of REP2139Ca intravenously once per week for 15 weeks, followed by 15 weeks of $250 \mathrm{mg}$ REP2139Ca+pegIFNo, then followed by 33 weeks of pegIFN $\alpha$ monotherapy (overall 63 weeks of therapy). ${ }^{82}$ At 24-week off-treatment follow-up, 5 (42\%) patients were HBsAg 
Recent advances in clinical practice

Table 1 Virological response in HDV patients treated with pegIFN $\alpha$, BLV with or without pegIFN $\alpha$, pegIFN $\lambda$, and LNF + RTV with or without peglFN $\alpha$

\begin{tabular}{|c|c|c|c|c|c|c|c|c|c|c|c|c|}
\hline \multirow[b]{4}{*}{ Treatment strategies } & \multirow{4}{*}{$\begin{array}{l}\begin{array}{l}\text { No of } \\
\text { patients }\end{array} \\
\text { Baseline }\end{array}$} & \multirow{4}{*}{$\begin{array}{l}\text { HDV RNA } \\
\text { levels (log } \\
\text { IU/ml) }\end{array}$} & \multirow{4}{*}{$\begin{array}{l}\text { Duration of } \\
\text { therapy } \\
\text { (weeks) }\end{array}$} & \multicolumn{9}{|c|}{ Virological response } \\
\hline & & & & \multicolumn{3}{|c|}{ HDV RNA $<$ LLoQ } & \multicolumn{3}{|c|}{$\begin{array}{l}\text { HDV RNA: }>2 \log I U / m L \text { decline or } \\
<\text { LLoQ }\end{array}$} & \multicolumn{3}{|c|}{$\begin{array}{l}\text { HDV RNA decline } \\
\text { (mean or median log IU/mL) }\end{array}$} \\
\hline & & & & \multicolumn{2}{|c|}{ During therapy } & \multirow{2}{*}{$\begin{array}{l}\text { Off-therapy } \\
\text { Week } 24\end{array}$} & \multicolumn{2}{|c|}{ During therapy } & \multirow{2}{*}{$\frac{\text { Off-therapy }}{\text { Week } 24}$} & \multicolumn{2}{|c|}{ During therapy } & \multirow{2}{*}{$\begin{array}{l}\text { Off-therapy } \\
\text { Week } 24\end{array}$} \\
\hline & & & & Week 24 & Week 48 & & Week 24 & Week 48 & & Week 24 & Week 48 & \\
\hline PegIFN $\alpha 180 \mu \mathrm{g}$ QW* & 15 & 5.44 & 48 & - & $13.3 \%$ & $0 \%$ & - & - & $0 \%$ & - & -1.29 & -0.26 \\
\hline $\begin{array}{l}\text { BLV } 2 \text { mg every day } \\
\text { mono* }\end{array}$ & 15 & 6.39 & 48 & $13 \%$ & $13.3 \%$ & $6.7 \%$ & - & - & $33.3 \%$ & - & -2.84 & -1.08 \\
\hline $\begin{array}{l}\text { BLV } 10 \mathrm{mg} \text { every day } \\
\text { mono* }\end{array}$ & 15 & 5.6 & 48 & $27 \%$ & $40 \%$ & $33.3 \%$ & - & - & $46.7 \%$ & - & -4.58 & - \\
\hline $\begin{array}{l}\text { BLV } 2 \mathrm{mg} \text { every day } \\
+ \text { pegIFN } \alpha 180 \mu \mathrm{g} \mathrm{QW}^{*}\end{array}$ & 15 & 5.48 & 48 & $67 \%$ & $80 \%$ & $53.3 \%$ & - & - & $73.3 \%$ & - & -5.21 & -4.04 \\
\hline $\begin{array}{l}\text { BLV } 10 \mathrm{mg} \text { every day } \\
+ \text { pegIFN } 180 \mu \mathrm{g} \mathrm{QW}\end{array}$ & 15 & 5.9 & 48 & $60 \%$ & $86.7 \%$ & $6.7 \%$ & - & - & $33.3 \%$ & - & -6.09 & - \\
\hline $\begin{array}{l}\text { LNF } 50 \mathrm{mg} \text { two times per } \\
\text { day+RTV } 100 \mathrm{mg} \text { two } \\
\text { times per dayt }\end{array}$ & 12 & - & 24 & $42 \%$ & - & - & $39 \%$ & - & - & -1.66 & - & - \\
\hline $\begin{array}{l}\text { LNF } 50 \mathrm{mg} \text { two times per } \\
\text { day+RTV } 100 \mathrm{mg} \text { two } \\
\text { times per day+pegIFN } \alpha \\
180 \mu \mathrm{g} \text { QW }\end{array}$ & 4 & - & 24 & $50 \%$ & - & - & $89 \%$ & - & - & -3.71 & - & - \\
\hline PegIFN $\lambda 180 \mu \mathrm{g} Q W \ddagger$ & 14 & 3.86 & 48 & - & $36 \%$ & $36 \%$ & - & - & - & -2.72 & -2.3 & -1.86 \\
\hline $\begin{array}{l}\text { LNF } 50 \mathrm{mg} \text { two times per } \\
\text { day+RTV } 100 \mathrm{mg} \text { two } \\
\text { times per day+pegIFN } \lambda \\
180 \mu \mathrm{g} \text { QW§ }\end{array}$ & 26 & 4.74 & 24 & $27 \%$ & - & $19 \%$ & $96 \%$ & - & - & -3.4 & - & - \\
\hline
\end{tabular}

*MYR203 study, HDV RNA assay LLoQ $10 \mathrm{IU} / \mathrm{mL}$

tLOWR-2 study, Robogene assay, LLoQ $14 \mathrm{IU} / \mathrm{mL}$.

‡LIMT study, Robogene assay, LLoQ $14 \mathrm{IU} / \mathrm{mL}$.

§LIFT HDV study, Quest Diagnostics Assay, HDV RNA LLoQ $<40 \mathrm{IU} / \mathrm{mL}$ or $<1.6 \mathrm{log} \mathrm{IU} / \mathrm{ml}^{\prime}$ ' -': data not published or not presented.

BLV, bulevirtide; HDV, hepatitis D virus; LNF, lonafarnib; pegIFN $\alpha$, pegylated interferon- $\alpha$; RTV, ritonavir.

negative, 5 (42\%) anti-HBs positive, 7 (58\%) with HBV DNA $<10 \mathrm{IU} / \mathrm{mL}$ and 7 (58\%) with negative HDV RNA by Robogene assay. A marked increase in ALT levels was observed after the introduction of pegIFN $\alpha$ in five patients but all remained asymptomatic. All patients experienced at least one adverse event, mostly pegIFN $\alpha$-related. The virological responses observed at week 24 off-therapy were confirmed when the off-treatment follow-up was extended up to 3 years. ${ }^{83}$
LNF with or without pegIFN $\alpha$

LNF is an orally administered inhibitor of farnesyl-transferase that blocks the prenylation of L-HDAg, showing an intracellular accumulation of RNPs and a dose-dependent reduction of serum HDV RNA. To optimise the risk-to-benefit ratio of this regimen, LNF was combined with ritonavir (RTV) to enable achieving higher (fourfold to fivefold) systemic exposure while improving its gastrointestinal tolerability, and with pegIFN $\alpha$

Table 2 Biochemical response in HDV patients treated with pegIFN $\alpha$, BLV with or without pegIFN $\alpha$, pegIFN $\lambda$, and LNF + RTV with or without pegIFN $\alpha$

\begin{tabular}{|c|c|c|c|c|c|c|}
\hline \multirow[b]{3}{*}{ Treatment strategies } & \multirow[b]{3}{*}{ Patients (n) } & \multirow{3}{*}{$\begin{array}{l}\text { ALT levels (U/L) } \\
\text { Baseline }\end{array}$} & \multirow[b]{3}{*}{ Duration of therapy (weeks) } & \multicolumn{3}{|c|}{ ALT normalisation } \\
\hline & & & & \multicolumn{2}{|c|}{ During therapy } & \multirow{2}{*}{$\begin{array}{l}\text { Off-therapy } \\
\text { Week } 24\end{array}$} \\
\hline & & & & Week 24 & Week 48 & \\
\hline PegIFN $\alpha 180 \mu \mathrm{g}$ QW* & 15 & 90 & 48 & - & $26.7 \%$ & $6.7 \%$ \\
\hline BLV 2 mg every day mono* & 15 & 84 & 48 & - & $66.6 \%$ & $20 \%$ \\
\hline BLV $10 \mathrm{mg}$ every day mono* & 15 & 73 & 48 & $60 \%$ & $40 \%$ & $33 \%$ \\
\hline BLV 2 mg every day +IFN $\alpha 180 \mu \mathrm{g}$ QW* & 15 & 70 & 48 & - & $26.7 \%$ & $46.7 \%$ \\
\hline BLV $10 \mathrm{mg}$ every day +pegIFN $\alpha 180 \mu \mathrm{g} \mathrm{QW}^{*}$ & 15 & 78 & 48 & $20 \%$ & $26.7 \%$ & $33 \%$ \\
\hline LNF $50 \mathrm{mg}$ two times per day+RTV $100 \mathrm{mg}$ ttwo times per day & 12 & - & 24 & $60 \%$ & - & - \\
\hline $\begin{array}{l}\text { LNF } 50 \mathrm{mg} \text { two times per day+RTV } 100 \mathrm{mg} \text { two times per } \\
\text { day+pegIFN } \alpha 180 \mu \mathrm{g} / \mathrm{QW}+\end{array}$ & 4 & - & 24 & $78 \%$ & - & - \\
\hline PegIFN $\lambda 180 \mu \mathrm{g} Q W \ddagger$ & 14 & - & 48 & - & $14 \%$ & $36 \%$ \\
\hline $\begin{array}{l}\text { LNF } 50 \mathrm{mg} \text { two times per day+RTV } 100 \mathrm{mg} \text { two times per } \\
\text { day+pegIFN } \lambda 180 \mu \mathrm{g} \text { QW§ }\end{array}$ & 26 & 64 & 24 & - & - & - \\
\hline $\begin{array}{l}\text { *MYR } 203 \text { study. } \\
\text { tLOWR-2 Study. } \\
\text { fLIMT Study. } \\
\text { §LIFT HDV Study, '-':data not published or not presented. } \\
\text { ALT, alanine aminotransferase; BLV, bulevirtide; HDV, hepatitis D vi }\end{array}$ & & 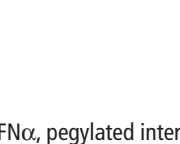 & & & & \\
\hline
\end{tabular}




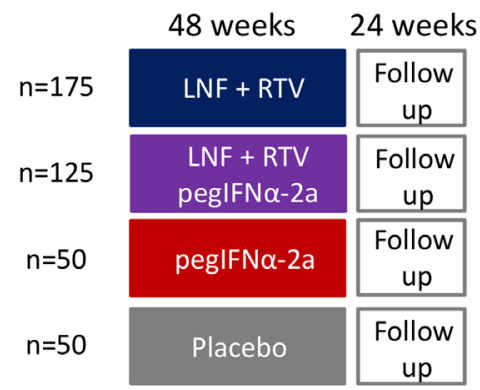

B

MYR301 study design

\begin{tabular}{|c|c|c|c|}
\hline & & 4 weeks & 96 weeks \\
\hline$n=50$ & $\begin{array}{l}\text { No HDV therapy } \\
\text { (48 weeks) }\end{array}$ & 10mg BLV QD & Follow up \\
\hline$n=50$ & & 2 mg BLV QD & Follow up \\
\hline$n=50$ & & 10mg BLV QD & Follow up \\
\hline
\end{tabular}

Figure 5 Study design of the two ongoing phase III studies assessing the efficacy and safety of new therapeutic regimens against HDV. (A) D-LIVR study. LNF +RTV: LNF $50 \mathrm{mg}$ two times per day+RTV $100 \mathrm{mg}$ two times per day. Primary endpoint: $\geq 2 \log 10 \mathrm{IU} / \mathrm{mL}$ decline in HDV RNA and ALT normalisation in week 48. All patients will be maintained on background HBV nucleoside/nucleotide analogue therapy. (B) MYR301 study. primary endpoint: undetectable HDV RNA or decrease by $\geq 2 \log 10 \mathrm{IU} / \mathrm{mL}$ and ALT normalisation in week 48. If indicated treatment with nucleoside/nucleotide analogues according to European Association for the Study of the Liver (EASL)/American Association for the Study of the Liver (AASLD) guidelines. ALT, alanine aminotransferase; BLV, bulevirtide; HBV, hepatitis B virus; HDV, hepatitis D virus; LNF, lonafarnib; pegIFN $\alpha$, pegylated interferon- $\alpha$; RTV, ritonavir;

to achieve a more profound inhibition of viral replication and HBsAg levels.

In the phase II LOWR HDV-2, 3 and 4 studies, ${ }^{84-86}$ the efficacy and safety of different doses of LNF+RTV in monotherapy or combined with pegIFN $\alpha$ administered for 12 or for 24 weeks were assessed. In summary, an all oral antiviral strategy based on LNF $50 \mathrm{mg}$ two times per day+RTV $100 \mathrm{mg}$ two times per day led to HDV RNA decline $\geq 2 \log$ or below the lower limit of quantification (LLoQ) in 39\% of patients (7 of 18) and ALT normalisation in $60 \%$ at week 24 (EOT) (tables 1 and 2). A combined therapy based on LNF + RTV + pegIFN $\alpha$ increased the EOT responses to $89 \%$ (8 of 9 ) and $78 \%$, respectively (tables 1 and 2). To date, the off-treatment virological or biochemical response rates of these regimens are not available.

\section{PegIFN $\lambda$ with or without LNF+RTV}

Lambda IFN binds a unique receptor vs type I IFN, highly expressed on hepatocytes, which may lead to a better safety profile of this compound compared with pegIFN $\alpha$.

The phase II LIMT HDV study evaluated the safety, tolerability, and efficacy of subcutaneous pegIFN $\lambda$ monotherapy administered at the dose of $120 v s 180 \mu \mathrm{g}$ QW in addition to TDF/entecavir (ETV) in 30 patients with chronic HBV/HDV coinfection $^{87}$ (tables 1 and 2). At week 72, by per-protocol (PP) analysis, the proportion of patients with undetectable HDV RNA, ALT normalisation and combined endpoints (ALT normalisation $+\geq 2 \log$ IU/mL HDV RNA decline vs BSL) was $16 \%$ vs $36 \%, 26 \%$ vs $36 \%$ and $11 \%$ vs $29 \%$. Adverse events typically seen with pegIFN $\alpha$ were fewer, but $10 \%$ of patients experienced hyperbilirubinaemia and ALT/AST increases, that were reversible with dose reduction and without any signs of decompensation.
In the open-label phase II single arm LIFT HDV study, 26 HDV patients received LNF+RTV+pegIFN $\lambda 180 \mu \mathrm{g}$ QW for 24 weeks $^{88}$ (tables 1 and 2). At week 24 (EOT), HDV-RNA decline was $3.2(2.5-4.0) \log \mathrm{IU} / \mathrm{ml}, 25 / 26$ (96\%) patients had a $>2 \log$ RNA decline and 11/26 (42\%) patients had HDV RNA undetectable or <LLoQ. Dose reductions were required in $3 / 26$ (11\%) patients and treatment discontinuation in 4/26 (15\%). At week 48, 24 weeks off-therapy, the virological response defined as HDV RNA < $40 \mathrm{IU} / \mathrm{mL}$ by Quest Diagnostics assay was $19 \%$ (5 of 26 patients) by intention-to-treat (ITT) analysis and 23\% (5 of 22) by PP analysis. ${ }^{89}$

\section{BLV with or without pegIFNa}

BLV, previously named Myrcludex-B, and approved in 2020 in Europe under the branded name of Hepcludex, is a subcutaneously delivered lipopeptide that mimics the NTCP RBD of the L-HBsAg, inhibiting the HBV/HDV entry into the hepatocytes (see previous section on virology).

\section{Short-term therapy}

In the multicentre phase IIb MYR202 study, ${ }^{90} 120$ TDF-treated patients with chronic HBV/HDV coinfection were randomised to different BLV doses $(2,5$ or $10 \mathrm{mg} /$ day $)$ or TDF monotherapy for 24 weeks. A 2-log decline or undetectable HDV RNA at EOT (week 24) was reached by $46 \%, 47 \%$ and $77 \%$ of the patients treated with increasing doses of BLV but only in 3\% of those on TDF monotherapy. ALT normalised in 43\%, 50\%, 40\%, and $6 \%$, while HBsAg levels were not affected. BLV was well tolerated, and elevation of glycine-conjugated and taurine-conjugated bile salts had no clinical consequences. An HDV-RNA relapse 


\section{Box 1 Open questions and future directions}

- Can hepatitis D virus (HDV) establish transcriptionally silenced but reactivatable episomes in hepatocytes as an additional mechanism of persistence?

- To what extent do the eight HDV genotypes differ in replication efficacy and sensitivity against the upcoming novel treatments?

- Do HDV-targeted therapies lead to a restoration of HDVspecific immunity?

- Are these restored immune responses required for treatment response? Are they required for prevention of viral relapse? of note, there may be differences in treatment regimens that are associated with alanine aminotransferase (ALT) flares (eg, REP2139Ca+pegylated interferon- $\alpha$ (IFN $\alpha$ ) combination therapy) compared with treatment regimens without ALT flares (eg, BLV monotherapy).

- How can a synergistic potential of antiviral drugs and immune-modulators be translated into curative regimens?

- Are there baseline or on-treatment predictors (eg, immune responses, kinetics of virological response) to sustained HDV virological response for the different treatment strategies?

- Is a sustained HDV virological response without hepatitis B surface antigen (HBsAg) loss a realistic and achievable aim for treatment regimens without IFNs?

- Are drugs aiming at HBsAg loss effective and safe in patients with chronic hepatitis B virus/HDV coinfection?

- Last but not least, since HDV is prevalent in low-income countries and migrant populations, it will be important to establish new concepts to foster diagnosis and access to care.

occurred in $60 \%, 80 \%$ and $83 \%$ of EOT HDV-RNA responders and was associated with a moderate increase in ALT levels.

In the phase II MYR203 study ${ }^{91}$ treatment with BLV, at different doses and with or without peg-IFN, was extended to 48 weeks (tables 1 and 2). 90 patients with chronic HBV/ HDV coinfection were randomised into six treatment arms. The primary efficacy endpoint, HDV RNA below the LLoD (10 IU/ $\mathrm{mL}$ ) at week 72 (24 weeks off-therapy), was achieved by $0 \%$, $53.3 \%, 26.7 \%, 6.7 \%, 6.7 \%$ and $33.3 \%$ of patients randomised to pegIFNo $180 \mathrm{QW}, 2 \mathrm{mg} \mathrm{BLV}+$ pegIFN $\alpha, 5 \mathrm{mg} \mathrm{BLV}+$ pegIFN, $5 \mathrm{mg}$ BLV, $10 \mathrm{mg}$ BLV + pegIFNa and $10 \mathrm{mg} \mathrm{BLV}$, respectively. The corresponding ALT normalisation rates were $10 \%$, $53.8 \%, 33.3 \%, 23.1 \%, 35.7 \%$ and $35.7 \%$. HBsAg loss or $>1 \log$ IU/ decline at week 72 was observed only in patients treated with BLV combined with pegIFN $\alpha$ : $40 \%$ for BLV $2 \mathrm{mg}, 13.3 \%$ for $5 \mathrm{mg}$ and $13.3 \%$ for $10 \mathrm{mg}$. BLV was generally well tolerated; an asymptomatic dose-related increase of total bile acids was observed. Most adverse events were observed in patients treated with pegIFN $\alpha$, without any difference between patients treated as a monotherapy or in combination with BLV.

\section{Long-term therapy}

Two patients with compensated HDV-related cirrhosis, one with oesophageal varices, were treated with BLV monotherapy $10 \mathrm{mg}$ for up to 3 years. $^{71}$ Both cases normalised ALT levels before week 28 and achieved undetectable HDV RNA $(<6 \mathrm{IU} / \mathrm{mL}$ by Robogene assay) before week 52. Biochemical and virological responses were maintained over 3 years of BLV administration without relapse or breakthrough, even after dose reduction of BLV from 10 to 5 and $2 \mathrm{mg} /$ day. ${ }^{92}$ In the patient with more severe liver disease, virological response was associated with an excellent clinical response: oesophageal varices disappeared, histological/laboratory features of autoimmune hepatitis secondary to HDV infection resolved, AFP levels normalised and liver stiffness, platelets and albumin levels significantly improved. As far as safety is concerned, only asymptomatic, dose-related increase of total bile acids was observed. The optimal duration of long-term therapy with BLV monotherapy is at present unknown although application of an HCV-based kinetics model to HDV-infected patients suggests that after 3 years of continuous suppression of HDV replication by BLV more than 50\% of the patients might achieve a long-term off-therapy virological response, despite persistence of HBsAg ${ }^{93}$ and unpublished data).

\section{New anti-HDV strategies: ongoing phase III studies}

Two multicentre international phase III registration studies are ongoing (figure 5). In the D-LIVR study (EIG-LNF-011), 400 patients with chronic HBV/HDV coinfection will be randomised to four treatment arms (figure 5A) for 48 weeks. The primary endpoint is the proportion of patients achieving $\mathrm{a} \geq 2 \log _{10} \mathrm{IU} / \mathrm{ml}$ reduction in serum HDV-RNA level and ALT normalisation at week 48 (EOT). In the MYR301 study, 150 patients with chronic $\mathrm{HBV} / \mathrm{HDV}$ coinfection have been randomised to three different arms (figure $5 \mathrm{~B}$ ). The primary objective is to evaluate the safety and efficacy of different doses of BLV monotherapy administered up to 144 weeks. The total duration of the study is 240 weeks.

\section{New therapeutic approaches targeting HBsAg}

Apart from the above-mentioned therapies, any new therapeutic that leads to functional cure in HBV monoinfected patients could be helpful in HBV/HDV coinfected ones. ${ }^{72}$ RNA interference and antisense oligonucleotides showed substantial declines of HBsAg in few weeks of administration in the absence of pegIFN, suggesting a potential role also in the treatment of coinfected patients.

\section{Current treatment options}

BLV at a dose of $2 \mathrm{mg}$ sc every day was approved by EMA in 2020 and is beside off-label use of pegIFN $\alpha$ the only treatment option, at least in the EU. FDA approval is pending. BLV could be used either in combination with pegIFN $\alpha$ (without formal EMA approval) or as monotherapy. A 'curative' strategy based on short-term (48 week) administration of sc daily injections of $2 \mathrm{mg}$ BLV combined with pegIFN $\alpha$ may result in HBsAg response and sustained off-therapy HDV-RNA negativity in some patients and may be used preferentially in those patients with wellcompensated disease. For the many HDV patients who cannot be treated with pegIFN $\alpha$ for different reasons, administration of BLV monotherapy may be a promising 'suppressive' strategy. However, the current data indicate that the approved low dose ( $2 \mathrm{mg}$ every day) is suboptimal and the optimal duration of highdose therapy and its long-term safety profile is currently investigated (MYR301 trial). Studies on the safety in patients with decompensated cirrhosis are required and a more convenient mode of administration or less frequent administrations would be desirable.

\section{CONCLUSIONS}

Forty years after the discovery of HDV, the first anti-HDV therapeutic has been approved in Europe, indicating the beginning of a new era for these difficult to treat/cure patients. Nevertheless, many questions related to HDV virology and immunology that 
affect sustained treatment responses to novel drugs remain to be solved (see box 1 'Open questions and future directions'), and a deeper understanding of virological and immunological mechanisms contributing to viral control will help to advance on the road to HDV eradication.

Acknowledgements We are grateful to Dr Zhenfeng Zhang for help with figures 1 and 2 .

Contributors All authors contributed to the writing of the manuscript and design of figures, and approved the final version.

Funding This work received funding by German Center for Infection Research (DZIF), TTU Hepatitis, project 5.704 (to SU) and 5.822 (to SU and CN-H) and the Deutsche Forschungsgemeinschaft TRR179 (project no. 272983813; TP15 and TP9 to $\mathrm{SU}, \mathrm{TP} 2$ to $\mathrm{CN}-\mathrm{H}$ )

Competing interests SU: Advisory Board/Speaker Bureau for: GILEAD SCIENCES, MYR, VIRBIO, ASSEMBLY, JANSSEN, ENYO, PEPPERPRINT, ALIGOS. CN-H: Speaker Bureau for: ABBVIE, Falk Foundation, Novartis, MSD. PL: Advisory Board/Speaker Bureau for: BMS, ROCHE, GILEAD SCIENCES, GSK, ABBVIE, MSD, ARROWHEAD, ALNYLAM, JANSSEN, SBRING BANK, MYR, EIGER.

Patient and public involvement Patients and/or the public were not involved in the design, or conduct, or reporting, or dissemination plans of this research.

Patient consent for publication Not required.

Provenance and peer review Not commissioned; externally peer reviewed.

Open access This is an open access article distributed in accordance with the Creative Commons Attribution Non Commercial (CC BY-NC 4.0) license, which permits others to distribute, remix, adapt, build upon this work non-commercially, and license their derivative works on different terms, provided the original work is properly cited, appropriate credit is given, any changes made indicated, and the use is non-commercial. See: http://creativecommons.org/licenses/by-nc/4.0/.

\section{ORCID iDs}

Christoph Neumann-Haefelin http://orcid.org/0000-0001-7351-1387

Pietro Lampertico http://orcid.org/0000-0002-1026-7476

\section{REFERENCES}

1 Lempp FA, Ni Y, Urban S. Hepatitis delta virus: insights into a peculiar pathogen and novel treatment options. Nat Rev Gastroenterol Hepatol 2016;13:580-9.

2 Lucifora J, Delphin M. Current knowledge on hepatitis delta virus replication. Antiviral Res 2020;179:104812.

3 Perez-Vargas J, Amirache F, Boson B, et al. Enveloped viruses distinct from HBV induce dissemination of hepatitis D virus in vivo. Nat Commun 2019;10:10.

4 Chemin I, Pujol FH, Scholtès C, et al. Preliminary evidence for hepatitis delta virus exposure in patients who are apparently not infected with hepatitis $B$ virus. Hepatology 2021;73:861-4.

5 Pflüger LS, Schulze Zur Wiesch J, Polywka S, et al. Hepatitis delta virus propagation enabled by hepatitis C virus-Scientifically intriguing, but is it relevant to clinical practice? J Viral Hepat 2021;28:213-6.

6 Cappy P, Lucas Q, Kankarafou N, et al. No evidence of HCV-assisted HDV propagation in a large cohort of hepatitis C positive blood donors. J Infect Dis 2021;223:1376-80.

7 Chen H-Y, Shen D-T, Ji D-Z, et al. Prevalence and burden of hepatitis D virus infection in the global population: a systematic review and meta-analysis. Gut 2019;68:512-21.

8 Miao Z, Zhang S, Ou X, et al. Estimating the global prevalence, disease progression, and clinical outcome of hepatitis delta virus infection. J Infect Dis 2020;221:1677-87.

9 Stockdale AJ, Kreuels B, Henrion MYR, et al. The global prevalence of hepatitis D virus infection: systematic review and meta-analysis. J Hepatol 2020;73:523-32.

10 Rizzetto M, Hamid S, Negro F. The changing context of hepatitis D. J Hepatol 2021;74:1200-11.

11 Alfaiate D, Clément S, Gomes D, et al. Chronic hepatitis D and hepatocellular carcinoma: a systematic review and meta-analysis of observational studies. $J$ Hepatol 2020;73:533-9.

12 Le Gal F, Brichler S, Drugan T, et al. Genetic diversity and worldwide distribution of the deltavirus genus: a study of 2,152 clinical strains. Hepatology 2017;66:1826-41.

13 Wang W, Lempp FA, Schlund F, et al. Assembly and infection efficacy of hepatitis $B$ virus surface protein exchanges in eight hepatitis $D$ virus genotype isolates. J Hepatol. In Press 2021. doi:10.1016/j.jhep.2021.03.025. [Epub ahead of print: 09 Apr 2021].

14 Hsu C-W, Juang H-H, Kuo C-Y, et al. Structural pattern differences in unbranched rodlike RNA of hepatitis delta virus affect RNA editing. Viruses 2019;11:934

15 Abeywickrama-Samarakoon N, Cortay J-C, Sureau C, et al. Hepatitis delta virus histone mimicry drives the recruitment of chromatin remodelers for viral RNA replication. Nat Commun 2020;11:419.
16 Casey JL. Control of ADAR1 editing of hepatitis delta virus RNAs. Curr Top Microbiol Immunol 2012:353:123-43.

17 Tu T, Urban S. Virus entry and its inhibition to prevent and treat hepatitis B and hepatitis D virus infections. Curr Opin Virol 2018;30:68-79.

18 Blanchet M, Sureau C. Infectivity determinants of the hepatitis B virus pre-S domain are confined to the N-terminal 75 amino acid residues. J Virol 2007;81:5841-9.

$19 \mathrm{Ni} \mathrm{Y}$, Sonnabend J, Seitz S, et al. The pre-S2 domain of the hepatitis B virus is dispensable for infectivity but serves a spacer function for L-protein-connected virus assembly. J Virol 2010;84:3879-88.

20 Freitas N, Cunha C, Menne S, et al. Envelope proteins derived from naturally integrated hepatitis B virus DNA support assembly and release of infectious hepatitis delta virus particles. J Virol 2014;88:5742-54.

21 Tu T, Budzinska MA, Shackel NA, et al. Hbv DNA integration: molecular mechanisms and clinical implications. Viruses 2017;9:75.

22 Yan $\mathrm{H}$, Zhong G, Xu G, et al. Sodium taurocholate cotransporting polypeptide is a functional receptor for human hepatitis B and D virus. Elife 2012;1:e00049.

23 Ni Y, Lempp FA, Mehrle S, et al. Hepatitis B and D viruses exploit sodium taurocholate co-transporting polypeptide for species-specific entry into hepatocytes. Gastroenterology 2014;146:1070-83

24 Yan Y, Allweiss L, Yang D, et al. Down-Regulation of cell membrane localized Ntcp expression in proliferating hepatocytes prevents hepatitis B virus infection. Emerg Microbes Infect 2019;8:879-94.

25 Billington S, Ray AS, Salphati L, et al. Transporter expression in noncancerous and cancerous liver tissue from donors with hepatocellular carcinoma and chronic hepatitis C infection quantified by LC-MS/MS proteomics. Drug Metab Dispos 2018;46:189-96.

26 Giersch K, Bhadra OD, Volz T, et al. Hepatitis delta virus persists during liver regeneration and is amplified through cell division both in vitro and in vivo. Gut 2019;68:150-7.

27 Zhang Z, Ni Y, Urban S. SAT-202-Endogenous and exogenous IFN responses suppress HDV persistence during proliferation of hepatocytes in vitro. J Hepatol 2019;70:e718-9.

28 Allweiss L, Volz T, Giersch K, et al. Proliferation of primary human hepatocytes and prevention of hepatitis $B$ virus reinfection efficiently deplete nuclear cccDNA in vivo. Gut 2018:67:542-52

29 Lempp FA, Schlund F, Rieble L, et al. Recapitulation of HDV infection in a fully permissive hepatoma cell line allows efficient drug evaluation. Nat Commun 2019;10:2265

30 Ni Y, Zhang Z, Engelskircher L, et al. Generation and characterization of a stable cell line persistently replicating and secreting the human hepatitis delta virus. Sci Rep 2019:9:10021.

31 Levesque K, Finzi A, Binette J, et al. Role of CD4 receptor down-regulation during HIV-1 infection. Curr HIV Res 2004:2:51-9.

32 Breiner KM, Urban S, Glass B, et al. Envelope protein-mediated down-regulation of hepatitis B virus receptor in infected hepatocytes. J Virol 2001;75:143-50

33 Burwitz BJ, Zhou Z, Li W. Animal models for the study of human hepatitis B and D virus infection: new insights and progress. Antiviral Res 2020;182:104898.

34 Tu T, Budzinska MA, Vondran FWR, et al. Hepatitis B Virus DNA Integration Occurs Early in the Viral Life Cycle in an In Vitro Infection Model via Sodium Taurocholate Cotransporting Polypeptide-Dependent Uptake of Enveloped Virus Particles. J Virol 2018;92:e02007-17

35 Tu T, Zehnder B, Qu B, et al. De novo synthesis of hepatitis B virus nucleocapsids is dispensable for the maintenance and transcriptional regulation of cccDNA. JHEP Rep 2021;3:100195.

36 Wooddell $\mathrm{Cl}$, Yuen M-F, Chan $\mathrm{HL}-\mathrm{Y}$, et al. Rnai-Based treatment of chronically infected patients and chimpanzees reveals that integrated hepatitis $B$ virus DNA is a source of HBsAg. Sci Trans/ Med 2017:9:eaan0241.

37 Zhang Z, Filzmayer C, Ni Y, et al. Hepatitis D virus replication is sensed by MDA5 and induces IFN- $\beta / \lambda$ responses in hepatocytes. J Hepatol 2018:69:25-35.

38 Koh C, Canini L, Dahari H, et al. Oral prenylation inhibition with lonafarnib in chronic hepatitis D infection: a proof-of-concept randomised, double-blind, placebo-controlled phase 2A trial. Lancet Infect Dis 2015;15:1167-74.

39 Beilstein F, Blanchet M, Vaillant A, et al. Nucleic Acid Polymers Are Active against Hepatitis Delta Virus Infection In Vitro. J Virol 2018;92. doi:10.1128/JVI.01416-17. [Epub ahead of print: 1502 2018].

40 Blanchet M, Sinnathamby V, Vaillant A, et al. Inhibition of HBsAg secretion by nucleic acid polymers in HepG2.2.15 cells. Antiviral Res 2019;164:97-105.

41 Vaillant A. Rep 2139: antiviral mechanisms and applications in achieving functional control of HBV and HDV infection. ACS Infect Dis 2019;5:675-87.

42 Verrier ER, Weiss A, Bach C, et al. Combined small molecule and loss-of-function screen uncovers estrogen receptor alpha and CAD as host factors for HDV infection and antiviral targets. Gut 2020;69:158-67.

43 Mutz P, Metz P, Lempp FA, et al. Hbv bypasses the innate immune response and does not protect HCV from antiviral activity of interferon. Gastroenterology 2018:154:1791-804

44 Suslov A, Boldanova T, Wang $X$, et al. Hepatitis B virus does not interfere with innate immune responses in the human liver. Gastroenterology 2018; 154:1778-90. 
45 Wieland S, Thimme R, Purcell RH, et al. Genomic analysis of the host response to hepatitis B virus infection. Proc Natl Acad Sci U S A 2004;101:6669-74.

46 Schwerk J, Negash A, Savan R, et al. Innate immunity in hepatitis C virus infection. Cold Spring Harb Perspect Med 2021;11. doi:10.1101/cshperspect.a036988. [Epub ahead of print: 01 Feb 2021].

47 Alfaiate D, Lucifora J, Abeywickrama-Samarakoon N, et al. Hdv RNA replication is associated with HBV repression and interferon-stimulated genes induction in superinfected hepatocytes. Antiviral Res 2016;136:19-31.

48 Giersch K, Allweiss L, Volz T, et al. Hepatitis delta co-infection in humanized mice leads to pronounced induction of innate immune responses in comparison to HBV mono-infection. J Hepatol 2015;63:346-53.

49 Zhang Z, Urban S. New insights into HDV persistence: the role of interferon response and implications for upcoming novel therapies. J Hepatol 2021;74:686-99.

50 Winer BY, Gaska JM, Lipkowitz G, et al. Analysis of host responses to hepatitis B and delta viral infections in a micro-scalable hepatic co-culture system. Hepatology 2020;71:14-30

51 Tham CYL, Kah J, Tan AT, et al. Hepatitis delta virus acts as an immunogenic adjuvant in hepatitis B virus-infected hepatocytes. Cell Rep Med 2020;1:100060.

52 Pugnale P, Pazienza V, Guilloux K, et al. Hepatitis delta virus inhibits alpha interferon signaling. Hepatology 2009;49:398-406.

53 Lunemann S, Malone DFG, Hengst J, et al. Compromised function of natural killer cells in acute and chronic viral hepatitis. J Infect Dis 2014:209:1362-73.

54 Malone DFG, Lunemann S, Hengst J, et al. Cytomegalovirus-driven adaptive-like natural killer cell expansions are unaffected by concurrent chronic hepatitis virus infections. Front Immunol 2017;8:525.

55 Actis GC, Maran E, Bonino F, et al. Patterns of natural killer cell function activation in response to interferon in chronic $\mathrm{HBSAg}$ positive hepatitis: relationship with the state of viral infection and with the early clinical response. J Biol Regul Homeost Agents 1987;1:45-50.

56 Lunemann S, Malone DFG, Grabowski J, et al. Effects of HDV infection and pegylated interferon $\alpha$ treatment on the natural killer cell compartment in chronically infected individuals. Gut 2015;64:469-82.

57 Provine NM, Klenerman P. MAIT cells in health and disease. Annu Rev Immunol 2020;38:203-28.

58 Dias J, Hengst J, Parrot T, et al. Chronic hepatitis delta virus infection leads to functional impairment and severe loss of MAIT cells. J Hepatol 2019;71:301-12.

59 Rizzetto M, Shih JW, Gocke DJ, et al. Incidence and significance of antibodies to delta antigen in hepatitis B virus infection. Lancet 1979;2:986-90.

60 Rehermann $B$, Thimme R. Insights from antiviral therapy into immune responses to hepatitis B and C virus infection. Gastroenterology 2019;156:369-83.

61 Landahl J, Bockmann JH, Scheurich C, et al. Detection of a broad range of low-level major histocompatibility complex class II-restricted, hepatitis delta virus (HDV)-specific T-cell responses regardless of clinical status. J Infect Dis 2019;219:568-77.

62 Nisini R, Paroli M, Accapezzato D, et al. Human CD4+ T-cell response to hepatitis delta virus: identification of multiple epitopes and characterization of T-helper cytokine profiles. J Virol 1997:71:2241-51.

63 Bertoletti A, Ferrari C. Adaptive immunity in HBV infection. J Hepatol 2016:64:571-83.

64 Karimzadeh H, Kiraithe MM, Oberhardt V, et al. Mutations in Hepatitis D Virus Allow It to Escape Detection by CD8 ${ }^{+} T$ Cells and Evolve at the Population Level. Gastroenterology 2019;156:1820-33.

65 Kefalakes H, Koh C, Sidney J, et al. Hepatitis D Virus-Specific CD8 ${ }^{+} T$ Cells Have a Memory-Like Phenotype Associated With Viral Immune Escape in Patients With Chronic Hepatitis D Virus Infection. Gastroenterology 2019;156:1805-19.

66 Huang Y-H, Tao M-H, Hu C-P, et al. Identification of novel HLA-A*0201-restricted CD8+ T-cell epitopes on hepatitis delta virus. J Gen Virol 2004;85:3089-98.

67 Karimzadeh H, Kiraithe MM, Kosinska AD, et al. Amino Acid Substitutions within HLAB*27-Restricted T Cell Epitopes Prevent Recognition by Hepatitis Delta Virus-Specific CD8 ${ }^{+}$T Cells. J Virol 2018;92. doi:10.1128/JVI.01891-17. [Epub ahead of print: 0107 2018].

68 Hensel N, Gu Z, Sagar WD. Memory-like HCV-specific CD8+ T cells retain a molecular scar after cure of chronic HCV infection. Nat Immunol 2021:22:229-39.

69 Schirdewahn T, Grabowski J, Owusu Sekyere S, et al. The third signal cytokine interleukin 12 rather than immune checkpoint inhibitors contributes to the functional restoration of hepatitis D virus-specific T cells. J Infect Dis 2017;215:139-49.

70 Wieland D, Kemming J, Schuch A, et al. TCF ${ }^{+}$hepatitis C virus-specific CD8 ${ }^{+} \mathrm{T}$ cells are maintained after cessation of chronic antigen stimulation. Nat Commun 2017:8:15050.
71 Loglio A, Ferenci P, Uceda Renteria SC, et al. Excellent safety and effectiveness of high-dose myrcludex-B monotherapy administered for 48 weeks in HDV-related compensated cirrhosis: A case report of 3 patients. J Hepatol 2019;71:834-9.

72 Cornberg M, Lok AS-F, Terrault NA, et al. Guidance for design and endpoints of clinical trials in chronic hepatitis B - Report from the 2019 EASL-AASLD HBV Treatment Endpoints Conference $\ddagger^{\ddagger}$.J Hepatol 2020;72:539-57.

73 Yurdaydin C, Abbas Z, Buti M, et al. Treating chronic hepatitis delta: the need for surrogate markers of treatment efficacy. J Hepatol 2019;70:1008-15.

74 European Association for the Study of the Liver. Electronic address: easloffice@ easloffice.eu, European Association for the Study of the Liver. EASL 2017 clinical practice guidelines on the management of hepatitis B virus infection. J Hepatol 2017;67:370-98.

75 Sarin SK, Kumar M, Lau GK, et al. Asian-Pacific clinical practice guidelines on the management of hepatitis B: a 2015 update. Hepatol Int 2016;10:1-98.

76 Terrault NA, Lok ASF, McMahon BJ, et al. Update on prevention, diagnosis, and treatment of chronic hepatitis B: AASLD 2018 hepatitis B guidance. Hepatology 2018:67:1560-99.

77 Heller T, Rotman Y, Koh C, et al. Long-Term therapy of chronic delta hepatitis with peginterferon alfa. Aliment Pharmacol Ther 2014;40:93-104.

78 Wedemeyer H, Yurdaydin C, Dalekos GN, et al. Peginterferon plus adefovir versus either drug alone for hepatitis delta. N Eng/ J Med 2011;364:322-31.

79 Wedemeyer H, Yurdaydin C, Hardtke S, et al. Peginterferon alfa-2a plus tenofovir disoproxil fumarate for hepatitis D (HIDIT-II): a randomised, placebo controlled, phase 2 trial. Lancet Infect Dis 2019:19:275-86.

80 Heidrich B, Yurdaydın C, Kabaçam G, et al. Late HDV RNA relapse after peginterferon alpha-based therapy of chronic hepatitis delta. Hepatology 2014;60:87-97.

81 Mederacke I, Filmann N, Yurdaydin C, et al. Rapid early HDV RNA decline in the peripheral blood but prolonged intrahepatic hepatitis delta antigen persistence after liver transplantation.J Hepatol 2012;56:115-22.

82 Bazinet M, Pântea V, Cebotarescu V, et al. Safety and efficacy of Rep 2139 and pegylated interferon alfa-2a for treatment-naive patients with chronic hepatitis B virus and hepatitis D virus co-infection (Rep 301 and Rep 301-LTF): a non-randomised, open-label, phase 2 trial. Lancet Gastroenterol Hepatol 2017;2:877-89

83 Bazinet M, Pântea V, Cebotarescu V, et al. Persistent control of hepatitis B virus and hepatitis delta virus infection following Rep 2139-Ca and pegylated interferon therapy in chronic hepatitis B virus/hepatitis delta virus coinfection. Hepatol Commun 2021;5:189-202

84 Koh C, Surana P, Han T, et al. A phase 2 study exploring once daily dosing of ritonavir boosted lonafarnib for the treatment of chronic delta hepatitis - end of study results from the LOWR HDV-3 study. J Hepatol 2017;66:S101-2.

85 Wedemeyer H, Port K, Deterding K, et al. A phase 2 dose-escalation study of Ionafarnib plus ritonavir in patients with chronic hepatitis $\mathrm{D}$ : final results from the Ionafarnib with ritonavir in HDV-4 (LOWR HDV-4) study. J Hepatol 2017:66:S24.

86 Yurdaydin C, Idilman R, Keskin O, et al. A phase 2 dose-optimization study of lonafarnib with ritonavir for the treatment of chronic delta hepatitis - end of treatment results from the LOWR HDV-2 study. J Hepatol 2017;66:S33-4.

87 Hamid SS, Etzion O, Lurie Y. A phase 2 randomized clinical trial to evaluate the safety and efficacy of pegylated interferon lambda monotherapy in patients with chronic hepatitis delta virus infection. interim results from the LIMT HDV study. Hepatology 2017;66.

88 Koh C, Hercun J, Rahman F, et al. A phase 2 study of peginterferon lambda, lonafarnib and ritonavir for 24 weeks: end-of-treatment results from the lift HDV study.J Hepatol 2020;73:S130

89 Koh C, Hercun J, Rahman F. A phase 2 study of peginterferon lambda, lonafarnib, and ritonavir for 24 weeks: end-of-study results from the lift HDV study. AASLD The Liver Meeting 2020.

90 Wedemeyer $\mathrm{H}$, Bogomolov $\mathrm{P}$, Blank $\mathrm{A}$, et al. Final results of a multicenter, open-labe phase $2 B$ clinical trial to assess safety and efficacy of Myrcludex $B$ in combination with tenofovir in patients with chronic HBV/HDV co-infection.J Hepatol 2018;68:S3.

91 Wedemeyer $\mathrm{H}$, Schöneweis K, Bogomolov PO, et al. 48 weeks of high dose (10 Mg) bulevirtide as monotherapy or with peginterferon alfa-2a in patients with chronic HBV/HDV co-infection.J Hepatol 2020;73:S52-3.

92 Loglio A, Ferenci P, Holzmann H. Myrcludex monotherapy in compensated cirrhotics with delta hepatitis: safety and effectiveness beyond two years of treatment in a reallife setting. Hepatology 2020;72.

93 Snoeck E, Chanu P, Lavielle M, et al. A comprehensive hepatitis C viral kinetic model explaining cure. Clin Pharmacol Ther 2010;87:706-13. 